\title{
TOR complex 2 is needed for cell cycle progression and anchorage-independent growth of MCF7 and PC3 tumor cells Ville Hietakangas ${ }^{* 1,2}$ and Stephen M Cohen ${ }^{1,2}$
}

\author{
Address: ${ }^{1}$ Temasek Life Sciences Laboratory, 1 Research Link, The National University of Singapore, 117604, Singapore and ${ }^{2}$ European Molecular \\ Biology Laboratory, Meyerhofstrasse 1, 69117 Heidelberg, Germany \\ Email: Ville Hietakangas* - ville@tll.org.sg; Stephen M Cohen - cohen@tll.org.sg \\ * Corresponding author
}

Published: 3 October 2008

BMC Cancer 2008, 8:282 doi:10.1 |86/|47|-2407-8-282

This article is available from: http://www.biomedcentral.com/I47I-2407/8/282

(c) 2008 Hietakangas and Cohen; licensee BioMed Central Ltd.

This is an Open Access article distributed under the terms of the Creative Commons Attribution License (http://creativecommons.org/licenses/by/2.0), which permits unrestricted use, distribution, and reproduction in any medium, provided the original work is properly cited.
Received: I February 2008

Accepted: 3 October 2008

\begin{abstract}
Background: AKT signaling promotes cell growth, proliferation and survival and is hyperactivated in many cancers. TOR complex 2 (TORC2) activates AKT by phosphorylating it on the 'hydrophobic motif' site. Hydrophobic motif site phosphorylation is needed only for a subset of AKT functions. Whether proliferation of tumor cells depends on TORC2 activity has not been thoroughly explored.

Methods: We used RNAi-mediated knockdown of rictor to inhibit TORC2 activity in MCF7 and PC3 tumor cells to analyze the importance of TORC2 on proliferation of tumor cells.

Results: TORC2 inhibition reduced proliferation and anchorage-independent growth of both cell lines. Rictor depleted cells accumulated GI phase, and showed prominent downregulation of Cyclin DI.

Conclusion: This study provides further evidence that inhibition of TORC2 activity might be a useful strategy to inhibit proliferation of tumor cells and subsequent tumor growth.
\end{abstract}

\section{Background}

AKT signaling promotes cell growth, proliferation and survival and is hyperactivated in numerous cancers (Reviewed in $[1,2]$ ). AKT kinase activity is principally determined by the level of phosphatidylinositol-3,4,5-triphosphate (PIP3) in the plasma membrane of cells, which is generated by phosphatidylinositol-3-kinase (PI3K) upon stimulation of receptor tyrosine kinases. PI3K is counteracted by the lipid-phosphatase and tumor suppressor PTEN, which converts PIP3 back to PIP2 (Reviewed in [1,2]). When PIP3 levels are elevated, AKT is recruited to the plasma membrane and phosphorylated in the activation loop by PDK1. In addition, AKT contains a highly conserved C-terminal hydrophobic motif (HM) that must also be phosphorylated for full AKT activation in vitro [3].

Recent studies in mammals and Drosophila have demonstrated that TORC2 is responsible for HM site phosphorylation [4-6]. Surprisingly, TORC2-mediated phosphorylation only affects a subset of AKT functions. MEFs lacking essential TORC2 components show reduced phosphorylation of FOXO, but not reduced phosphorylation of TSC2 or GSK-3, although all three are well-established AKT targets $[7,8]$. In Drosophila, TORC2 loss-offunction phenotypes are substantially different from those of the other AKT pathway members [6]. While Drosophila AKT and its upstream regulators, such as PI3K and 
PDK1, are essential for viability and cell growth, flies lacking TORC2 are viable and display only minor growth impairment under standard growth conditions. However, TORC2 is required for tissue overgrowth upon hyperactivation of AKT signaling, e.g. in the case of PTEN loss-offunction. This suggests that TORC2 inhibitors might be a useful for treating cancers that depend of high AKT signaling. Since TORC2-mediated phosphorylation is essential for only a subset of AKT functions, it is possible that targeting TORC2, instead of other AKT pathway members, would minimize unwanted consequences resulting from more general inhibition of AKT activities.

In order to evaluate the potential of TORC2 inhibition in cancer treatment, it is important to analyze which AKT functions depend on TORC2 in malignant cells. Here we have analyzed the effects of TORC2 inhibition on proliferation and anchorage independent growth in two different tumor cells, MCF7 breast cancer and PC3 prostate cancer cells. Inhibition of TORC2 activity by knockdown of an essential component, Rictor, inhibited cell cycle progression, cell proliferation and anchorage-independent growth in both cell types. Our results suggest that inhibition of TORC2 activity might be a useful strategy to inhibit proliferation of tumor cells and subsequent tumor growth.

\section{Methods \\ Cell culture and treatments}

MCF7 and PC3 cells were maintained in DMEM with 10\% FCS and penicillin/streptomycin in humidified $5 \% \mathrm{CO}_{2}$ atmosphere at $37^{\circ} \mathrm{C}$. The siRNAs targeting human rictor were Hs_AVO3_1 (target sequence: AAACAAGGCTGTGATTCTA) and Hs_AVO3_2 (target sequence: AAAGACTACAGCAACAAAGAA; Qiagen). The negative control (non-silencing) siRNA had target sequence AATTCTCCGAACGTGTCACGT. siRNAs were transfected by using HiPerFect reagent (Qiagen) according to manufacturer's protocol. For AKT kinase assays, cells were treated with Insulin (Sigma, $10 \mu \mathrm{g} / \mathrm{ml}$ ) and wortmannin (Sigma, 50 $\mathrm{nM}$ ) for $20 \mathrm{~min}$.

\section{Western blotting and AKT kinase assay}

After treatments cells were washed once with cold PBS and lysed by boiling in Laemmli sample buffer, resolved on SDS-PAGE, transferred to nitrocellulose membrane and blotted with the following antibodies: anti-AKT phosphoS473, anti-AKT, anti-Cyclin D1 (Cell Signaling Technology), anti-Rictor (Bethyl Laboratories), anti-GAPDH (Santa Cruz Biotechnology). AKT kinase assay was purchased from Cell Signaling Technology and used according to the manufacturer's protocol. The intensities of the phospho-GSK3 bands were quantified by using the ImageJ software (NIH \#3877). The total levels of GSK-3 crosstide fusion protein were visualized by Coomassie staining.

\section{Proliferation and cell death assays}

Cells were plated at low density, transfected with siRNAs and allowed to proliferate for 2 days. After that, cells were trypsinized, diluted, plated, re-transfected, and allowed to proliferate another four days. Cells were counted with a counting chamber. For analyzing the amount of cell death, cells were seeded on chambered slides and transfected with the siRNAs for 4 days. Cells were fixed with $4 \%$ paraformaldehyde and nuclei were stained with DAPI. Cells were imaged by confocal microscopy and condensed nuclei were calculated. Cell death and nuclear condensation in MCF7 cells was induced by staurosporin treatment $(1 \mu \mathrm{M} / 3 \mathrm{~h})$.

\section{Soft agar assay}

0.5\% agar ( $1.5 \mathrm{ml} / 35 \mathrm{~mm}$ plate) containing DMEM, 10\% FCS, and penicillin/streptomycin was used as base agar. Two days after siRNA transfection, 5000 cells were seeded into $1.5 \mathrm{ml}$ of $0,35 \%$ medium-containing agar that was plated on top of the base agar. The plates were incubated in humidified $5 \% \mathrm{CO}_{2}$ atmosphere at $37^{\circ} \mathrm{C}$ for 21 days, stained with $0.5 \mathrm{ml}$ of $0.005 \%$ Crystal Violet for $1 \mathrm{~h}$ and counted using a microscope.

\section{Cell cycle analysis}

Three days after transfection cells were collected, washed by PBS and fixed with $70 \%$ ethanol on ice for $1 \mathrm{~h}$. Fixed cells were stained with propidium iodine $(20 \mu \mathrm{g} / \mathrm{ml})$ in the presence of RNAse A $(200 \mu \mathrm{g} / \mathrm{ml})$ in PBS with $0.1 \%$ Triton X-100 for $15 \mathrm{~min}$ in $37^{\circ} \mathrm{C}$. Stained cells were analyzed by flow cytometry.

\section{Results \\ Rictor depletion inhibits AKT phosphorylation and activity in MCF7 and PC3 tumor cells}

In order to analyze the importance of TOR complex 2 for growth of tumor cells, we sought to prevent its activity by downregulating Rictor, an essential component of TORC2 $[9,10]$. We used two independent siRNAs directed against rictor mRNA and, as a control, an siRNA not targeting any human proteins. Both rictor siRNAs efficiently lowered Rictor protein levels in MCF7 and PC3 cells, compared to cells transfected with control siRNA (Fig. 1A).

TORC2 phosphorylates AKT on the hydrophobic motif site, which led us to analyze the effect of Rictor knockdown on this phosphorylation event. Immunoblot analysis showed that Rictor depletion led to strong inhibition of AKT hydrophobic motif phosphorylation in both cell lines, whereas total levels of AKT remained unaltered (Fig. 1A). To directly analyze the effect of Rictor depletion on AKT kinase activity, we performed a kinase assay, by 

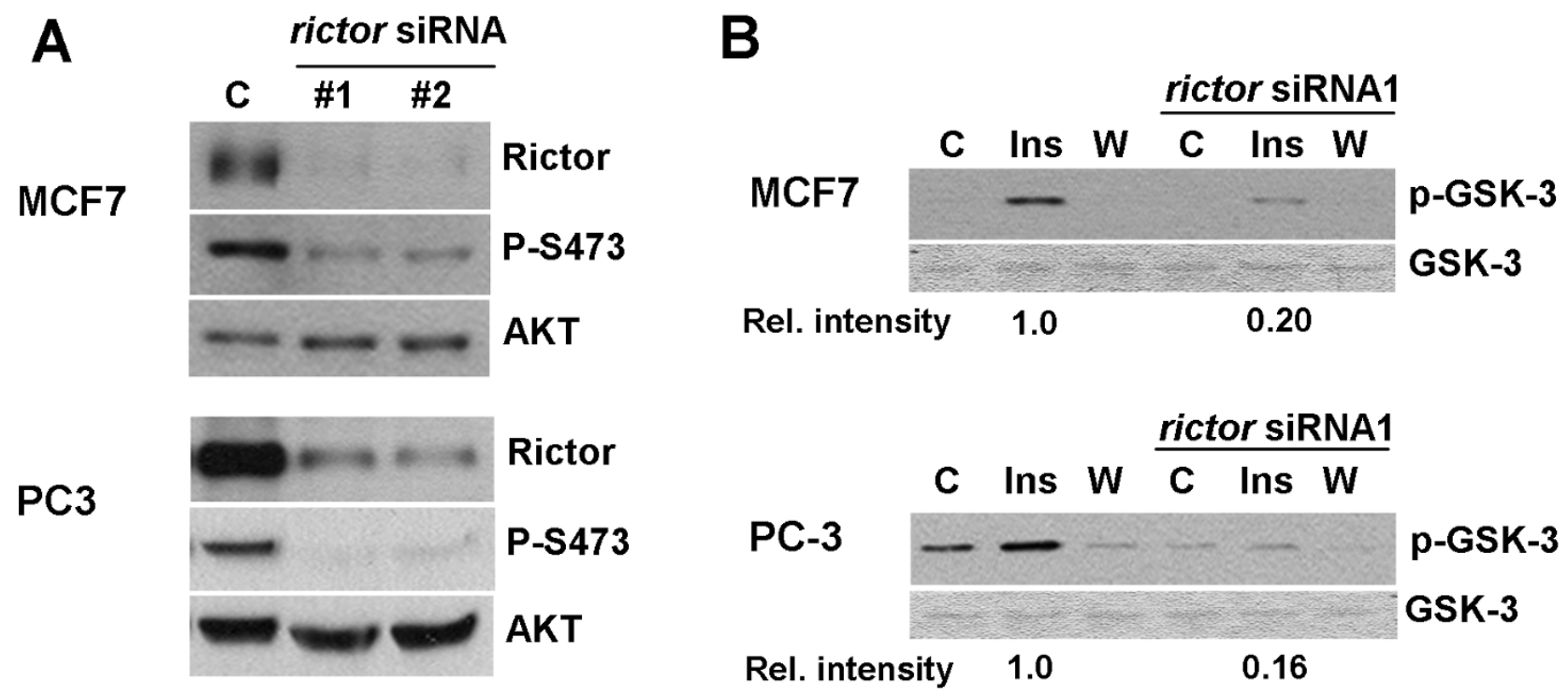

Figure I

Rictor depletion reduces AKT HM phosphorylation and inhibits AKT kinase activity. (A) MCF7 and PC3 cells were treated for five days with two independent siRNAs against rictor or with a control siRNA not targeting any human protein. Cells were lysed by boiling in sample buffer and proteins resolved by SDS-PAGE. Levels of Rictor expression and AKT phosphorylation and expression were analyzed by immunoblotting with anti-Rictor, anti-AKT and antibody specific for the phosphorylated form of the HM site, P-S473. (B) Cells were treated for five days with rictor siRNA, treated with insulin (Ins) or wortmannin (W) or left untreated (C). Cells were lysed and AKT was immunopurified with immobilized AKT antibodies. To measure AKT kinase activity, the immunoprecipitates were incubated with paramyosin-fused GSK-3 crosstide in the presence of ATP. The level of phosphorylation was analyzed by blotting with antibodies specific to phospho-GSK-3. Total GSK-3 level is shown as a loading control.

immunoprecipitating AKT and assaying its ability to phosphorylate in vitro a protein containing a GSK-3 peptide harboring a consensus phosphorylation site for AKT. As expected, AKT kinase activity was induced when cells were treated with insulin and inhibited by PI3K inhibitor wortmannin (Fig. 1B). In line with the strongly reduced AKT hydrophobic motif phosphorylation, the insulin-induced AKT kinase activity was reduced to $20 \%$ in both cell lines upon Rictor depletion (Fig. 1B).

\section{Inhibition of tumor cell proliferation and anchorage independent growth upon Rictor depletion}

As an initial assessment for the effects of TORC2 inhibition, we analyzed the amount of cell death and the rate of proliferation of MCF7 and PC3 cells upon Rictor depletion. Controlled amounts of siRNA-transfected cells were plated at low density and allowed to proliferate for several days. During the growth period, rictor siRNAs did not cause significant increase in cell death, observed either by the extent of cell detachment (data not shown) or by analyzing nuclear morphology (Fig. 2A). Intriguingly, cell counts indicated that Rictor depletion strongly inhibited proliferation of MCF7 cells (Fig. 2B). Proliferation of PC3 cells was also significantly inhibited, albeit less strongly than in the case of MCF7 cells (Fig. 2B).

Anchorage-independent growth is a hallmark of transformed cells that correlates well with their ability to be invasive and metastatic. AKT activity is crucial for tumor growth, not only because it promotes proliferation, but because it allows anchorage-independent growth by preventing detachment-induced apoptosis, anoikis [11]. Therefore, we performed a more stringent test to evaluate the importance of TORC2 in respect to tumor cell growth by analyzing the anchorage-independent growth of the MCF7 and PC3 cells after Rictor depletion. The control siRNA-treated cells formed colonies in soft agar (Fig. 3A, B), but transfection of rictor siRNA almost totally abolished the formation of colonies, demonstrating that TORC2 activity is required for anchorage-independent growth of MCF7 and PC3 cells (Fig. 3A, B).

\section{Accumulation of cells in GI phase and downregulation of Cyclin DI upon rictor knockdown}

Previous work has shown that AKT activity is needed for G1/S progression during the cell cycle, which can be 
A

MCF7

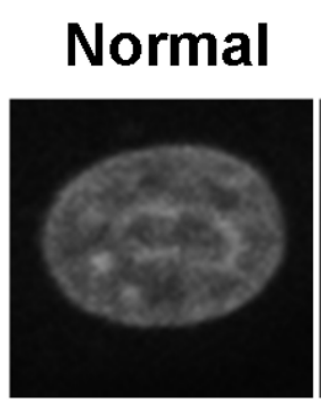

PCD

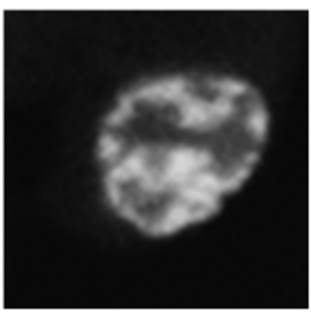

PC3

Normal
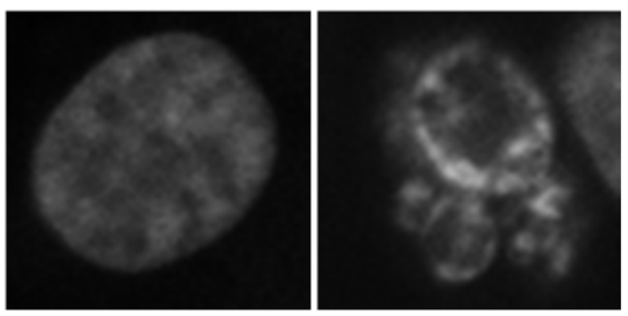

\begin{tabular}{lrrr} 
& \multicolumn{1}{c}{ Control } & rictor SI-1 & rictor SI-2 \\
\cline { 2 - 4 } MCF7 & $0 \% / 167$ & $0 \% / 129$ & $0 \% / 94$ \\
PC3 & $5.1 \% / 157$ & $5.0 \% / 119$ & $8.5 \% / 142$
\end{tabular}

B

MCF7

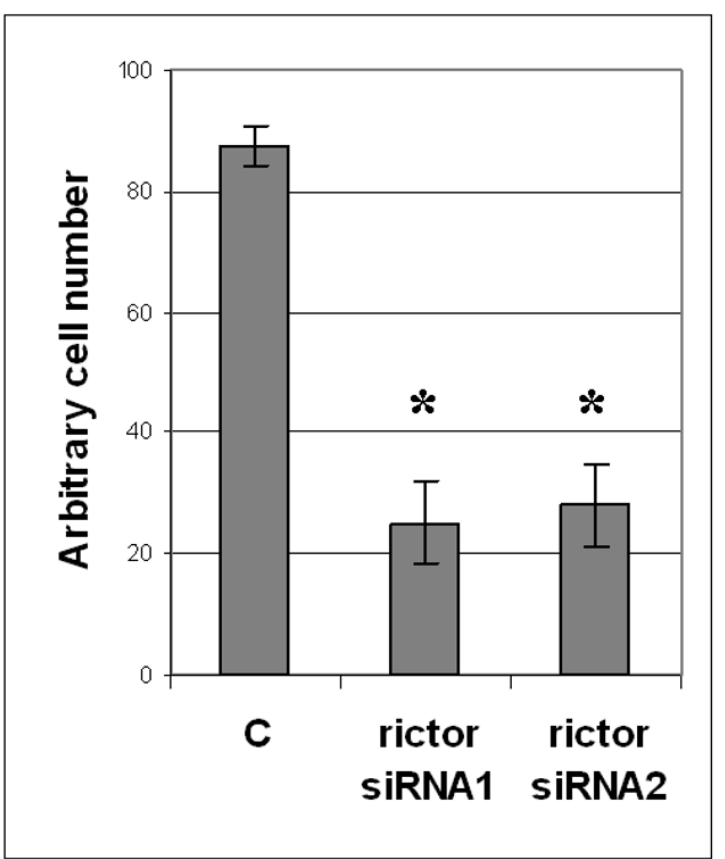

PC3

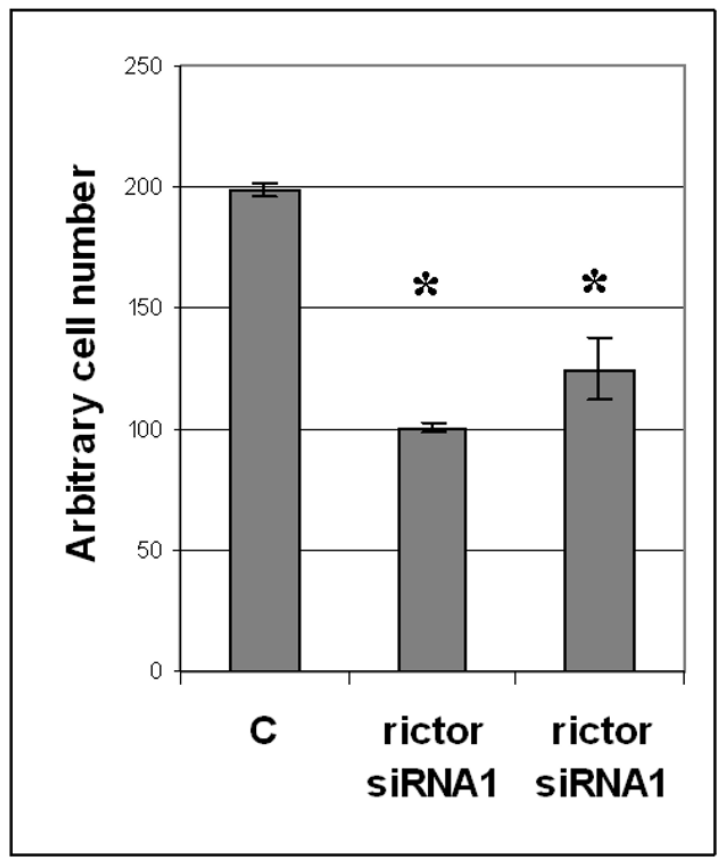

Figure 2 (see legend on next page) 
Figure 2 (see previous page)

Inhibition of TORC2 reduces proliferation of MCF7 and PC3 cells. (A) The amount of programmed cell death (PCD) was analyzed by calculating the percentage of cells displaying nuclear condensation 4 days after siRNA treatments. In the table the percentage of condensed nuclei and the number of cells analyzed is displayed. Note that MCF7 cells lack functional caspase3, which makes them resistant and affects their mode of cell death [20]. When treated with the commonly used cell death inducer, staurosporin, MCF7 cells undergo nuclear condensation without the nuclear fragmentation typical of normal apoptotic cells (upper panel). (B) MCF7 and PC3 cells were plated at low density and transfected with two independent rictor siRNAs or with a control siRNA. Cells were allowed to proliferate for two days until they reached near confluency, they were trypsinized, diluted and replated at low density and retransfected with the siRNAs. Cells were allowed to proliferate another four days until the control cells were nearly confluent. Cells were trypsinized, resuspended and counted with a counting chamber. All samples were done in three replicates. $*$ Students t-test $\mathrm{p}<0.01$.

explained, at least partially, by regulation of Cyclin D1 levels [12], reviewed in [13]. To examine whether the reduced rate of proliferation upon TORC2 inhibition might be explained by inhibition of cell cycle progression, we analyzed the effects of Rictor depletion on the cell cycle profile. Both MCF7 and PC3 cells displayed a clear enrichment of cells in G1 when treated with the siRNAs against Rictor (Figure 4A). MCF7 cells showed a shift from

A

MCF7

Control siRNA rictor SiRNA1

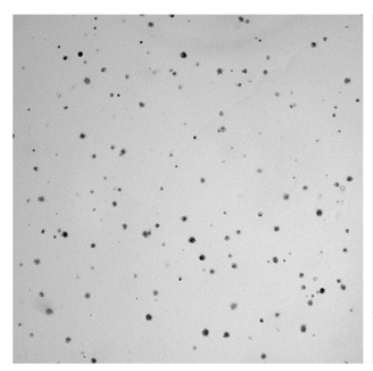

B

Control siRNA rictor siRNA1

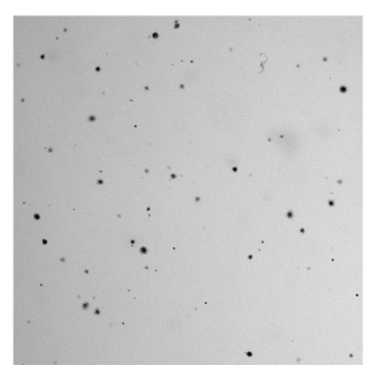

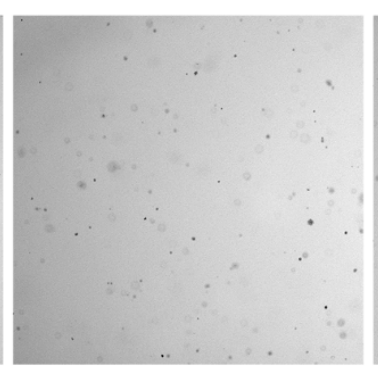

rictor SIRNA2

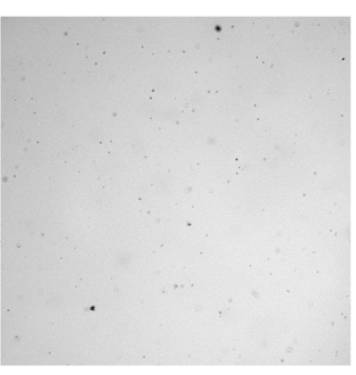

PC-3

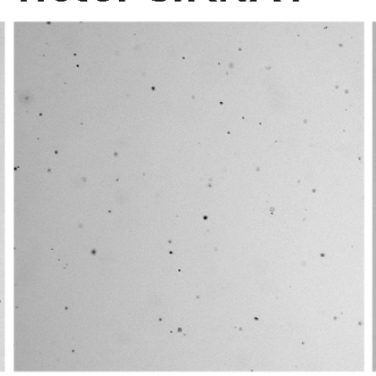

rictor SiRNA2

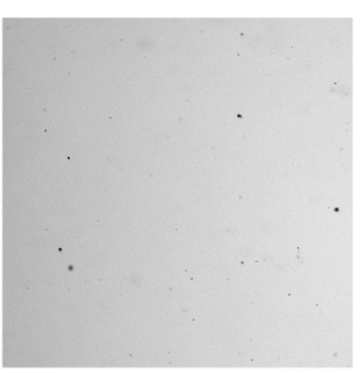

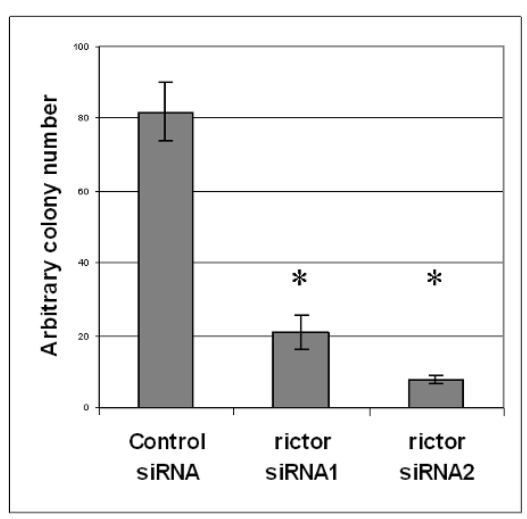

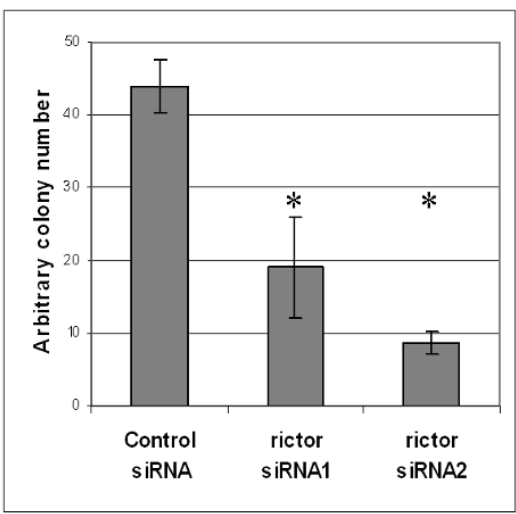

\section{Figure 3}

Inhibition of anchorage independent growth upon Rictor depletion. (A) MCF7 and PC3 cells were transfected with the siRNAs. Two days after transfection cells were detached with trypsin and seeded into soft agar. Colonies were allowed to grow for three weeks after which they were stained with crystal violet. (B) The number of visible colonies in a defined area was counted in three replicate samples. * Student's t-test $\mathrm{p}<0.01$. 
A
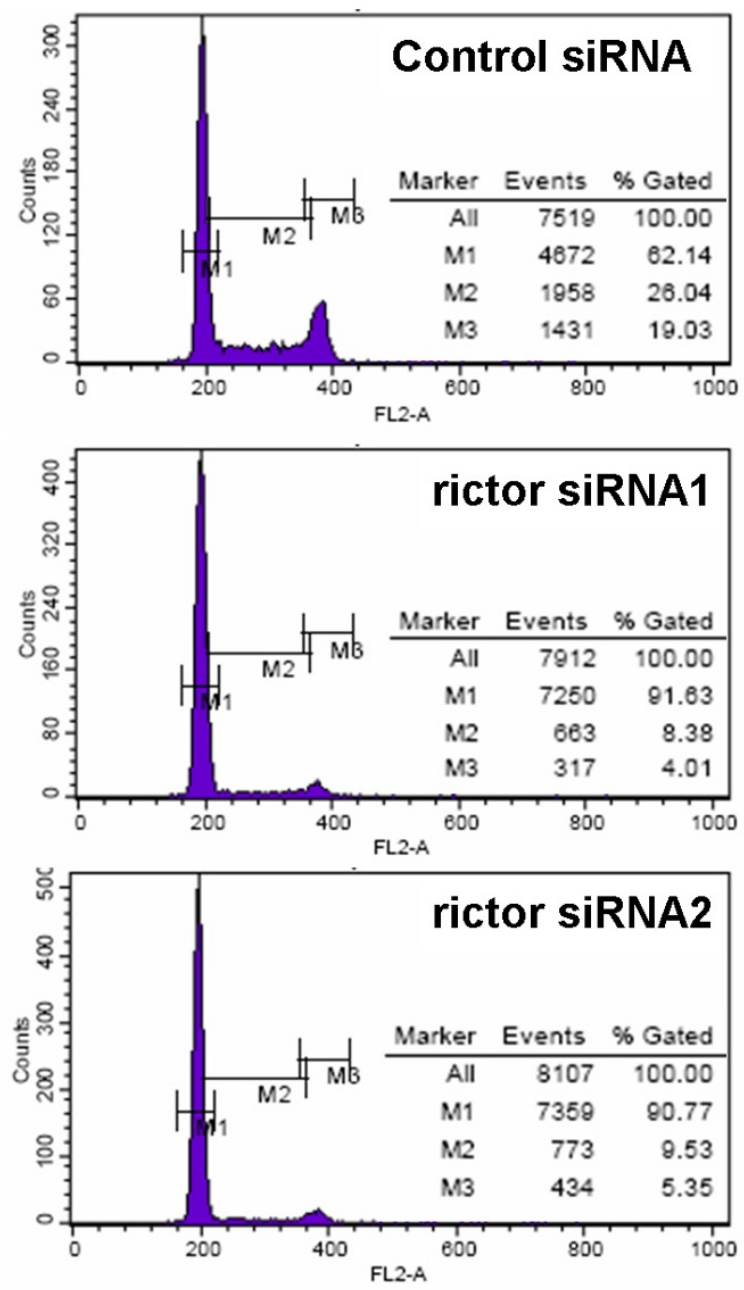

B

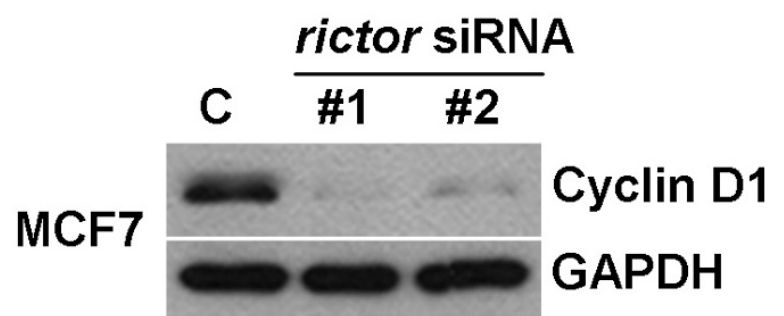

PC3
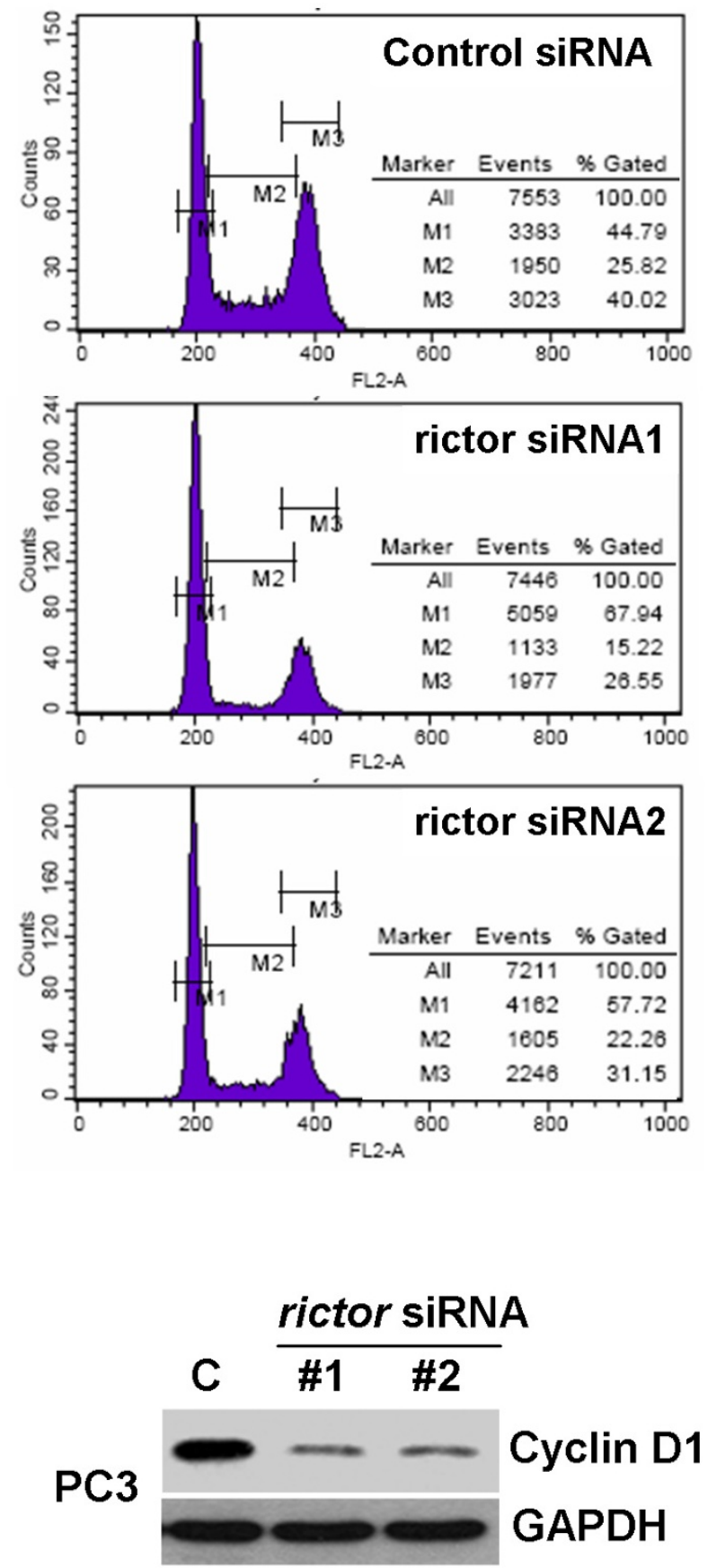

Figure 4

Accumulation of cells in GI phase upon rictor depletion correlates with downregulation of Cyclin DI. (A) Flow cytometry histograms showing accumulation of cells in GI phase after depletion of rictor. Cells were treated with siRNAs for five days, fixed with ethanol, stained with propidium iodine. DNA content was analyzed by flow cytometry. MI: GI, M2: S, M3: G2/M phase. (B) Cells were treated with control or rictor siRNAs for five days. Cyclin DI levels were analyzed by immunoblotting with anti-CyclinDI. GAPDH was used as loading control. 
$\sim 60 \%$ to $>90 \%$ of cells in G1. The effect was similar, but less pronounced in PC3 cells. We next analyzed Cyclin D1 levels by immunoblotting after Rictor depletion. Rictor depletion strongly reduced the expression of Cyclin D1 (Figure 4B), suggesting that phosphorylation of the hydrophobic motif of AKT is needed to maintain Cyclin D1 expression and subsequent cell cycle progression.

\section{Discussion and conclusion}

In order to evaluate the potential of TORC2 inhibition as a strategy to impair tumor cell proliferation, we have analyzed the consequences of Rictor depletion in two distinct tumor cell lines MCF7 and PC3. Inhibition of TORC2 activity prevented proliferation and anchorage independent growth of both MCF7 and PC3 cells, although MCF7 were more sensitive to reduced TORC2 activity. Analysis of cell cycle profiles revealed a clear enrichment of cells in G1 phase in TORC2-inhibited cells, which coincided with a strong downregulation of Cyclin D1. These findings suggest that loss of HM site phosphorylation may be sufficient to mimic the effects of a more global inhibition of AKT activity in this context, although we cannot rule out the possibility of AKT-independent effects. In sum, our study shows that proliferation and anchorage-independent growth of tumor cells can be efficiently prevented by inhibiting TORC2, which therefore could be an effective strategy for treatment of cancers that depend on high AKT activity.

Which AKT functions are dependent on TORC2-mediated HM phosphorylation? Several studies provide evidence that two downstream effectors of AKT, FOXO1/3a and TORC1, respond differently to loss of AKT HM phosphorylation. In both Drosophila and mammalian systems, loss of TORC2 activity reduces phosphorylation-mediated inhibition of FOXO, whereas TORC1 activity is unaffected by loss of AKT HM phosphorylation [4,6-8]. This difference is reflected in the Drosophila TORC2 loss-of-function phenotypes. While loss of AKT, Rheb or TOR cause a clear reduction of cell size [14-16], inhibition of TORC2, and consequently AKT HM phosphorylation, does not (VH \& SC, unpublished observation). FOXO1/3a, on the other hand, has been shown to be important for regulation of resistance to oxidative stress and other apoptotic stimuli, and indeed mammalian cells lacking TORC2 or AKT HM phosphorylation are hypersensitive to apoptotic stimuli induced by $\mathrm{H}_{2} \mathrm{O}_{2}$ [7], indole-3-carbinol [17] or etoposide [5]. The effect of TORC2 on cell proliferation has been studied in fibroblasts derived from knock-out mouse models of essential TORC2 components Rictor and $\operatorname{Sin} 1$ with controversial results. Shiota and coworkers analyzed proliferation of Rictor-deficient MEFs and showed that the cells displayed modestly slower proliferation compared to wild type [18], whereas Jacinto and coworkers analyzed sin1-deficient MEFs, and found that they proliferated similarly to wild type cells [7]. In the two tumor cell lines analyzed here, acute loss of TORC2 activity clearly slowed proliferation by slowing or blocking cells in G1 phase of the cell cycle. Interestingly, a recent study showed that many gliomas overexpress Rictor and have elevated TORC2 activity that contributes to their tumorigenity [19]. Results obtained in our study suggest that the potential of preventing tumor growth by inhibition of TORC2 is not only limited to gliomas, but can be used to inhibit growth of other types of tumors as well.

Sarbassov and coworkers discovered that prolonged treatments with rapamycin or its derivatives can also inhibit TOR complex 2, in addition to the well-established inhibition of TORC1 [17]. Therefore, rapamycin derivatives might be useful in preventing growth of tumors dependent on AKT HM phosphorylation. However, strong inhibition of TORC1 may have undesirable consequences. Therefore development of small-molecular inhibitors specific to TORC2 is necessary.

\section{Competing interests}

The authors declare that they have no competing interests.

\section{Authors' contributions}

$\mathrm{VH}$ planned experiments, performed experiments, analyzed data, and wrote the manuscript. SC planned experiments, analyzed data, and wrote the manuscript. Both authors have read and approved the final manuscript.

\section{Acknowledgements}

We thank Andy Riddell from the EMBL Flow Cytometry Core Facility for technical assistance and Thomas Sandmann for comments for the manuscript. V.H. was supported by the Academy of Finland, 'Helsingin Sanomain I00-vuotissäätiö' (Finland), and the Marie Curie Intra-European Fellowship.

\section{References}

I. Bhaskar PT, Hay N: The two TORCs and Akt. Dev Cell 2007, I 2(4):487-502.

2. Manning BD, Cantley LC: AKT/PKB signaling: navigating downstream. Cell 2007, I 29(7): $126 \mid-1274$.

3. Alessi DR, Andjelkovic M, Caudwell B, Cron P, Morrice N, Cohen P, Hemmings BA: Mechanism of activation of protein kinase $B$ by insulin and IGF-I. Embo J 1996, I 5(23):654I-655I.

4. Sarbassov DD, Guertin DA, Ali SM, Sabatini DM: Phosphorylation and regulation of Akt/PKB by the rictor-mTOR complex. Science 2005, 307(57 | 2): 1098-I I01.

5. Yang Q, Inoki K, Ikenoue T, Guan KL: Identification of Sin I as an essential TORC2 component required for complex formation and kinase activity. Genes Dev 2006, 20(20):2820-2832.

6. Hietakangas $V$, Cohen SM: Re-evaluating AKT regulation: role of TOR complex 2 in tissue growth. Genes Dev 2007, $21(6): 632-637$.

7. Jacinto E, Facchinetti V, Liu D, Soto N, Wei S, Jung SY, Huang Q, Qin J, Su B: SINI/MIP I maintains rictor-mTOR complex integrity and regulates Akt phosphorylation and substrate specificity. Cell 2006, I27(I):125-137.

8. Guertin DA, Guntur KV, Bell GW, Thoreen CC, Sabatini DM: Functional genomics identifies TOR-regulated genes that control growth and division. Curr Biol 2006, I 6 ( I 0):958-970.

9. Jacinto E, Loewith R, Schmidt A, Lin S, Ruegg MA, Hall A, Hall MN: Mammalian TOR complex 2 controls the actin cytoskeleton 
and is rapamycin insensitive. Nat Cell Biol 2004, 6(I I): II22-I I 28.

10. Sarbassov DD, Ali SM, Kim DH, Guertin DA, Latek RR, ErdjumentBromage H, Tempst P, Sabatini DM: Rictor, a novel binding partner of $m T O R$, defines a rapamycin-insensitive and raptorindependent pathway that regulates the cytoskeleton. Curr Biol 2004, I 4( I 4): I 296-I302.

II. Khwaja A, Rodriguez-Viciana P, Wennstrom S, Warne PH, Downward ]: Matrix adhesion and Ras transformation both activate a phosphoinositide 3-OH kinase and protein kinase B/Akt cellular survival pathway. Embo J 1997, I 6(1 0):2783-2793.

12. Diehl JA, Cheng M, Roussel MF, Sherr C): Glycogen synthase kinase-3beta regulates cyclin DI proteolysis and subcellular localization. Genes Dev 1998, I 2(22):3499-35 I I.

13. Liang J, Slingerland JM: Multiple roles of the PI3K/PKB (Akt) pathway in cell cycle progression. Cell Cycle 2003, 2(4):339-345.

14. Verdu J, Buratovich MA, Wilder EL, Birnbaum MJ: Cell-autonomous regulation of cell and organ growth in Drosophila by Akt/PKB. Nat Cell Biol I999, I(8):500-506.

I5. Zhang H, Stallock JP, Ng JC, Reinhard C, Neufeld TP: Regulation of cellular growth by the Drosophila target of rapamycin dTOR. Genes Dev 2000, I4(2 I):27I2-2724.

16. Stocker H, Radimerski T, Schindelholz B, Wittwer F, Belawat P, Daram P, Breuer S, Thomas G, Hafen E: Rheb is an essential regulator of S6K in controlling cell growth in Drosophila. Nat Cell Biol 2003, 5(6):559-565.

17. Sarbassov DD, Ali SM, Sengupta S, Sheen JH, Hsu PP, Bagley AF, Markhard AL, Sabatini DM: Prolonged rapamycin treatment inhibits mTORC2 assembly and Akt/PKB. Mol Cell 2006, 22(2): $159-168$.

18. Shiota C, Woo JT, Lindner J, Shelton KD, Magnuson MA: Multiallelic disruption of the rictor gene in mice reveals that $m$ TOR complex 2 is essential for fetal growth and viability. Dev Cell 2006, I I(4):583-589.

19. Masri J, Bernath A, Martin J, Jo OD, Vartanian R, Funk A, Gera J: mTORC2 activity is elevated in gliomas and promotes growth and cell motility via overexpression of rictor. Cancer Res 2007, 67(24): II712-I I720.

20. Tang D, Lahti JM, Kidd VJ: Caspase-8 activation and bid cleavage contribute to MCF7 cellular execution in a caspase-3dependent manner during staurosporine-mediated apoptosis. J Biol Chem 2000, 275(I 3):9303-9307.

\section{Pre-publication history}

The pre-publication history for this paper can be accessed here:

http://www.biomedcentral.com/1471-2407/8/282/pre

pub
Publish with Biomed Central and every scientist can read your work free of charge

"BioMed Central will be the most significant development for disseminating the results of biomedical research in our lifetime. "

Sir Paul Nurse, Cancer Research UK

Your research papers will be:

- available free of charge to the entire biomedical community

- peer reviewed and published immediately upon acceptance

- cited in PubMed and archived on PubMed Central

- yours - you keep the copyright
BiolMedcentral 